\title{
La Constitución o Producción de la Subjetividad, del Sujeto Desde el Psicoanálisis y del Sujeto SuJETAdo al Discurso de la “DiscaPacidaD”
}

\author{
Blanca Estela Zardel Jacobo ${ }^{1}$ \\ Universidad Nacional Autónoma de México - UNAM
}

Resumen

Se presenta una travesía desde cuatro recorridos. El primero, incursiona en una reflexión de la subjetividad desde dos miradas; la que parte de la subjetividad como inherente al sujeto bajo tres dimensiones: bio-psico-social. Su estudio requiere posicionarlo como objeto y abordarlo con métodos cuantitativos y cualitativos que demuestren su confiabilidad y validez. La otra aproximación se apoya en disciplinas sociales cuyo punto de partida es considerar al sujeto desde una subjetividad que se fundamenta desde una exterioridad social e histórica. El segundo abordará la constitución del sujeto desde el psicoanálisis, considerando a Freud y Lacan como los autores prioritarios. El tercer recorrido realizará un desplazamiento o construcción histórica de la mirada y discurso de la discapacidad como "atributo" o condición del sujeto, de la producción de la discapacidad como figura o modalidad de una otredad paralizante y el cuarto y último, introduce una mirada que subvierte la mirada de la discapacidad y realiza efectos de ruptura, resignificación y/o reestructuración. En el marco de algunas prácticas desde ámbitos del arte y del deporte, se encuentran ya formas de vida de ciertas personas, que pese a todo el destinar social a la exclusión, están mostrando, con su vivir día a día ámbitos donde la investigación debe incursionar e iniciar, con ellos y con otros profesionales, indagaciones que se aproximen a otras formas alternas de ser y estar en el mundo, es decir a las modalidades de otras subjetividades e identidades.

Keywords: producción de la subjetividad, diferencia, otredad, inconsciente; discapacidad.

\section{The Construction or Production of Subjectivty, of Subject From Psychoanlisis AND OF SUBJECT SUBJECTED TO DisABILITY DisCOURSE.}

\begin{abstract}
A cruise is presented from four tours. The first ventures into a reflection of subjectivity from two perspectives; which part of the subjectivity inherent in the subject under three dimensions: bio-psycho-social. Their study requires position it as object and approach it with quantitative and qualitative methods to demonstrate their confiability and validity. The other approach is based on social disciplines whose starting point is to consider the subject from a subjectivity that is produced from a social and historical externality. The second route will address the constitution of the subject from psychoanalysis, Freud and Lacan considering as priority authors. The third route will make a shift or historical construction of disability against the point of view of considering disability as an "attribute" or condition of the subject,
\end{abstract}

${ }^{1}$ E-mail: zardelj@gmail.com 
la constitución o producción de la subjetividad, del sujeto desde el psicoanálisis y del sujeto sujetado al discurso de la "discapacidad"

It will work from the perspective of production of disability as a figure or mode of a stun otherness. The fourth and last, introduces a look that subverts the look of disability and makes breaking effects, new meaning and / or restructuring. Under some practices from areas of art and sport, are already lifestyles of certain individuals, that despite all the social allocate to exclusion, are showing with their day to day living areas where research must venture and start with them and with other professionals, inquiries to the manner of other subjectivities and identities approaching other alternative ways of being and being in the world.

Keywords: Production of subjectivity; difference; otherness; unconscious; disability.

\section{A Constituição ou Produção da Subjetividade, do Sujeito a PARTIR da Psicanálise e O SUJEITO SUJEITADO AO DisCURSO DA “DEFICIÊNCIA"}

Resumo

Apresenta-se uma travessia a partir de quatro percursos. O primeiro, incursiona em uma reflexão da subjetividade a partir de dois olhares; a que parte da subjetividade como inerente ao sujeito sob três dimensões: bio-psico-social. Seu estudo requer posicioná-lo como objeto e aborda-lo com métodos quantitativos e qualitativos que demonstrem sua confiabilidade e validade. A outra aproximação se apoia em disciplinas sociais cujo ponto de partida é considerar o sujeito a partir de uma subjetividade que se fundamenta em uma exterioridade social e histórica. O segundo abordará a constituição do sujeito a partir da psicanálise, considerando Freud e Lacan como os autores prioritários. O terceiro percurso realizará um desdobramento ou construção histórica do olhar e discurso da deficiência como "atributo" ou condição do sujeito, da produção da deficiência como figura ou modalidade de uma outridade paralisante e o quarto e último, introduz um olhar que subverte o olhar da deficiência e realiza efeitos de ruptura, ressignificação e/ou reestruturação. No marco de algumas práticas do âmbito da arte e do esporte, já se encontram formas de vida de certas pessoas, que mesmo com o destinar social à exclusão, estão mostrando, com seu viver dia a dia âmbitos onde a investigação deve incursionar e iniciar, com eles e com outros profissionais, indagações que se aproximem a outras formas alternativas de ser e estar no mundo, quer dizer, às modalidades de outras subjetividades e identidades.

Palavras-chave: produção da subjetividade, diferença, outridade, inconsciente; deficiência. 


\section{Introducción}

Este trabajo da expresión a una travesía de una trayectoria profesional que desde los años 80s del siglo pasado ha incursionado en el ámbito denominado actualmente como discapacidad. Se pretende introducir un diálogo a través de cuatro recorridos que intentan polemizar con el discurso dominante sobre el sujeto con discapacidad. Los recorridos se presentan en un orden, sin embargo no se dieron sucesivamente en la indagación, sino como un intento de exponer ante el lector una reorganización de la travesía para poner los puntos que se consideran relevantes en el abordaje de otra aproximación al ámbito de la discapacidad. De esta manera se dan los antecedentes que de alguna manera se concretan en los recorridos.

La primera interrogación fue en los 80 del siglo pasado, a la discapacidad como substancia, como atributo naturalizado del sujeto. Nos preguntábamos si las condiciones sociales, económicas y políticas, que si bien se señalaban como importantes, no se consideraban como dimensiones de producción del "fenómeno" discapacidad. Al mismo tiempo las prácticas de formación de estudiantes de psicología en la atención a niños considerados en aquel entonces con retardo en el desarrollo y sus familias nos permitieron interrogarnos sobre las vicisitudes la subjetividad. El psicoanálisis nos auxilió en comprender las paradojales consecuencias que se observaban en las intervenciones, los conflictos, la impotencia, y la complejidad y heterogeneidad de dimensiones por lo que la concepción del sujeto, el yo, la individuación y la subjetividad se tornó imprescindible. La incursión a las aproximaciones de la subjetividad nos llevó a la indagación desde perspectivas filosóficas y sociales y los cuestionamientos al cogito cartesiano. De ello dará cuenta el primer recorrido. Paralelamente el estudio del psicoanálisis permitió fundamentar preguntas sobre la constitución del sujeto con discapacidad, por ello, el segundo recorrido da una aproximación a este enfoque. Con estos dos se emprendió una tarea de indagación sobre la conformación del campo de la discapacidad y del discurso oficial sobre los inicios y las etapas por las que ha pasado para fundamentar la 
la constitución o producción de la subjetividad, del sujeto desde el psicoanálisis y del sujeto sujetado al discurso de la "discapacidad"

apertura de un ámbito de exploración y deconstrucción de la hegemonía de una mirada a la discapacidad considerada en falta. Desde la episteme de la fundación del sujeto desde la exterioridad social nos permitimos ir abordando otro enfoque sobre la discapacidad y llevar a cabo estudios en las prácticas que llevan a un cambio en la significación dominante de la misma. Para ello se requirió una exploración de cómo se gestó la visibilidad y discursividad del ámbito de la educación especial y cómo fueron emergiendo las propuestas de integración e inclusión como promesa del combate a la discriminación y exclusión. Emprendimos una incursión documental para dar cuenta cómo se fue construyendo una mirada y discurso de la discapacidad como "atributo" o condición del sujeto; de la producción de la discapacidad como figura o modalidad de una otredad paralizante e ir aproximándonos a una mirada que subvierte una identidad incapacitante por los efectos de ruptura y reestructuración que en la documentación y análisis de las prácticas sociales se iban vislumbrando. La introducción de las aproximaciones de diferencia, y alteridad posibilitaron orientar la perspectiva que desmontaba un concepción de discapacidad, e introducirla como una diferencia productora, generadora, creativa, de formas alternas de ser y estar en el mundo. En el tercer y cuarto recorrido se expresa esto último y se propone como una apertura al debate y la indagación.

\section{La constitución o producción de la subjetividad}

En nuestra contemporaneidad se constatan ciertos saberes reconocidos y legitimados desde la medicina, la biología, la psicología, el derecho, entre otros, que sostienen cierta conceptualización de normatividad o forma de vida social que comprende ámbitos desde la salud, alimentación, desarrollo físico, mental y social para poder llevar a cabo una vida acorde a los nobles fines que una sociedad aspira.

El Estado ha sido la figura que procura proveer los bienestares esperados para, en términos de los modelos biológicos, satisfacer las necesidades trasladadas a la condición social-cultural-humana, que van más allá del orden de una sobrevivencia biológica. Se desprende por ello, los derechos universales de todo ser humano a la 
salud, a la alimentación, a la educación, al trabajo, a la libertad de expresión, a la recreación, etc. Las instituciones que velan por la salud y la educación serán las que proveen las posibilidades para la emergencia y preparación a la vida social. Se requiere de preservar la salud y que todo individuo tenga acceso a la educación para que pueda llevar a cabo, acorde a su preparación, las capacidades y habilidades individuales que desarrolle y logre alcanzar, a través del trabajo remunerado que corresponda a su empeño y esfuerzo, el proyecto de vida que le permita realizar una vida digna. El Estado tendrá la responsabilidad de proveer las condiciones externas y el sujeto a través de su individuación lograr lo que se propone. En esta regulación y equilibrio, cada ciudadano podrá encontrar un lugar y la realización de desarrollar sus capacidades e insertarse en la vida productiva a través de una remuneración o salario equivalente a lo que reditúa su trabajo. El salario se supone ser lo suficiente para adquirir, alcanzar y disfrutar los beneficios de una vida digna para él y los que se encuentran bajo su responsabilidad y cuidado².

Estos planteamientos que hoy en la actualidad encuentran un tope con la lacerante realidad, no por ello dejan de ser una aspiración, y se sostienen en la gestión o misión de las instituciones que presten servicios en el ámbito de la salud y de la educación. Asimismo, cualquier curriculum, o plan de estudio, proyecto o discurso académico se sostiene en lo que Horkheimer (1973) denominó la racionalidad instrumental. Es decir, los dirigentes del rumbo de la vida social no pueden renunciar a la aspiración de la consecución de ideales, de la conducción hacia un rumbo de progreso, de ascenso, de avance y hasta de vanguardia del cambio y de un porvenir que resuelva las adversidades del presente. Los servicios y las instancias educativas se fundamentarán en comparsa con los ideales y contribuirán desde sus especialidades al alcance de:

\footnotetext{
2 Sólo basta revisar los Planes de Desarrollo Sexenales de los Presidentes de México, o bien los Programas de Instituciones de formación de profesionales, los objetivos siempre apuntan al logro del desarrollo del bienestar social, a la resolución de problemáticas.
} 
la constitución o producción de la subjetividad, del sujeto desde el psicoanálisis y del sujeto sujetado al discurso de la "discapacidad"

a) la salud previniendo, combatiendo y reduciendo las problemáticas endémicas o emergentes, concentradas en lo que se denomina la enfermedad, lo que impide la salud, lo que se le opone, a la salud. Su finalidad es avanzar hacia una prolongación y una calidad de vida lo más alta posible; que no pocas veces encuentra sus contradicciones entre longevidad y enfermedades derivadas muchas de ellas de la misma producción de longevidad;

b) la educación se encargará de otro ascenso, progreso y porvenir: el del pasaje de la niñez a la ciudadanía, lo cual se logra a través de su legado histórico, científico, cívico y la transmisión del conocimiento como valor capital. Asimismo, el docente tendrá el papel de mediador entre esta transmisión generacional del capital cultural simbólico y promoverá el proceso de aprendizaje de los educandos desde sus intereses y procesos de desarrollo a través de los procedimientos o métodos metodológicos que instrumente el docente. La formación tiene como meta no sólo el máximo desarrollo del educando, sino que el fin educativo rebasa lo individual. Los educandos se transformarán en los mejores "instrumentos" para el desarrollo del país en las diversas áreas que se requieran. Se encuentran ligados tanto los fines individuales como los fines sociales. He ahí una moral formativa del Bien (individual y social), una espiral que al mismo tiempo que provee las herramientas para la consecución de las metas individuales, las trascienda al fin máximo social. Contribuir al bienestar en sus diversas modalidades: productivas, de servicio, recreativo, cultural, del ocio y creativo. Por ello quizá el mito depositado en los profesionales, en los docentes como los agentes catalizadores del progreso. El enlace entre esta base moral se reforzará a través del derecho, de la jurisdicción, del poder judicial, encargado del equilibrio entre derechos y obligaciones, de la vigilancia, prevención y rehabilitación de lo que la normatividad haya sancionado como fuera de la Ley y siempre dispuesto a lograr la justicia social. Constatamos como los paradigmas actuales de vanguardia, sean los de la diversidad, los de inclusión y los de la sustentabilidad repercuten en los cuerpos ejecutivo y legislativo del Estado. Por leyes 
y dictaminaciones no ha parado el Estado en apuntalar las metas de la inclusión, la diversidad y la equidad de oportunidades. ${ }^{3}$

De esta manera se encuentran engranado, no sin contradicción, los diversos sistemas sociales en un dispositivo estructural que mantengan una lógica encaminada en su discurso hacia una forma de vida humana implícitamente validada. La formación de profesionales se encauza en la travesía por los saberes y prácticas constituidas para mantener y promover una forma de vida deseable y reparar, rehabilitar, componer, sancionar o resolver las problemáticas reconocidas por la época así como de promover el desarrollo industrial, científico y productivo de un país.

Y sin embargo El Malestar se manifiesta cada vez con mayor diversidad en las diversas esferas de la vida social quebrantando e imposibilitando el cumplimiento de las promesas de bienestar, no obstante, los individuos mantengan el empeño por alcanzarlo. Se constata la queja, el enojo e inconformidad de los ciudadanos, al mismo tiempo que las condiciones sociales los ponen en situaciones más precarias y vulnerables. Inclusive se ven amenazadas sus propias posibilidades de existencia. La sobrevivencia, la vida misma se encuentra en peligro ante la inseguridad y violencia. En lo económico se encuentra un contraste. Mayor índice de riqueza de unos pocos y mayores índices de pobreza en la población. No se diga del resto: índices de enfermedades provocadas como la diabetes, estrés, problemas respiratorios, cáncer, etc.

Lo anterior convive con contrastes apabullantes como el alto avance científico y tecnológico, producciones de saberes, amplitud, diversidad y creación de conocimientos con repercusiones en los diversos ámbitos de la vida social que presentan el lado luminoso y esperanzador. Es insospechada la producción de capital tecnológico con aplicaciones en todos los ámbitos de la vida humana y la naturaleza que sin duda resultan de admiración y que pueden enaltecer las formas de vida

\footnotetext{
${ }^{3}$ Constantemente en los medios de difusión se proclaman todas las regulaciones, dictámenes y reformas de avanzada por los cuerpos legislativos.
} 
la constitución o producción de la subjetividad, del sujeto desde el psicoanálisis y del sujeto sujetado al discurso de la "discapacidad"

social. Por sólo mencionar algunos ejemplos en el ámbito de la salud. Se han generado tratamientos que combaten enfermedades que se pensaban mortales, el cáncer, por ejemplo. En educación, investigación y desarrollo científico tenemos el impulso a las ciencias exactas y en el ámbito de las Humanidades que abordan lo social. La hibridación de disciplinas desde la bioética, bio-genéticas y un auge en la multi, inter y transdisciplinas. Paradigmas innovadores, propuestas epistémicas y una aproximación a lo plural heterogéneo. El empleo de las TICs en los procesos formativos y coadyuvan al proceso de enseñanza-aprendizaje.

Llegamos al punto de estar en una encrucijada ante un panorama desolador real en la condición de vida de una gran mayoría de personas a nivel global que es real, y al mismo tiempo, también es real el impulso, creación y producciones inéditas que posibilitan una transformación de las condiciones sociales de existencia inéditas. Aceleradamente vemos una globalización no sólo económica sino política y cultural, al mismo tiempo que lo local, regional, identidades cobra relevancia e importancia. Diversidad, inclusión, tolerancia, precariedad, diferencia, alteridad, otredad, mismidad son referentes conceptuales para interrogar las propuestas educativas, sociales y culturales.

En esta disertación, nos parece que cobra sentido el ámbito de lo académico, de la investigación como tarea de reflexión permanente, del pensar que produce acontecimiento.

Este término lo introduce Heidegger (1964) y da lugar al sentido de producción como obra, creación, transformación, advenimiento, aparición, en el sentido de hacer obra, algo inesperado, algo diferente que se realiza desde un pensar que es dar cuenta de la mirada y del decir o de lo dicho, desde un pasado que no ha pasado, sino que constituye un futuro anterior de nuestro presente. Una historia posibilitadora de experiencia, de instaurar a partir del origen la reivindicación de la experiencia como diferencia (AGAMBEN, 2007). 
Este modo de producir visibiliza las formas de constitución humana entendida como subjetividad, concepto que desde la filosofía y ciertas disciplinas sociales $\mathrm{y}$, de manera particular el psicoanálisis, se demarcan de la dualidad tendenciosa de pretender lo Objetivo como lo científico y lo Subjetivo como lo que tiene que quedar fuera para validar y legitimar el conocimiento.

El pensar, la experiencia y el acontecimiento se entraman en la constitución de la subjetividad como una condición de historia y transformación, de ir más allá del sujeto comprendido como yo-conciencia, una unidad que decide, tiene libertad y apunta hacia la realización de las metas que se proponga. No se aborda desde la tríada: bio-psico-social sino que la individuación, la constitución de subjetividad se produce desde una exterioridad social, fundante, de ahí que toda constitución de un yo viene de otro, y de Otro. De ahí los términos de Diferencia como separación, como hiancia, grieta, agujero, falta irreductible, carencia proveniente de la discontinuidad con la naturaleza en su pasaje al orden social, humanizante. Entre esa Otredad como origen, se instala un "olvido", un acontecer de inconsciente entre el yo y el otro, del otro y del semejante. De un Otro al otro, como se intitula el seminario XVI de Lacan (1964). El Otro desde Lacan asume una función de terceridad, de esa función que denomina registro simbólico, estructura del Significante, del orden de la lengua como tercero y preexistente a la relación intersubjetiva. Otra manera de decirlo será desde el término heideggeriano de imagen o visión de mundo (HEIDEGGER, 2008). En cuanto a la relación intersubjetiva objetivada desde el registro simbólico se producirá el registro imaginario. Relación del uno con el otro, mi semejante, un diferente al que me asemejo, me identifico. De ahí la constitución narcisista, especular entre el uno y el otro como base para la identificación. Esta relación imaginaria se instituye desde una relación tensional, de afirmación y negación, es y no es al mismo tiempo esa imagen del semejante y su devolución. De ahí el término fruediano de la identidad como narcisismo, el engaño entre la imagen, reflejo que a manera de espejo instaura 
la constitución o producción de la subjetividad, del sujeto desde el psicoanálisis y del sujeto sujetado al discurso de la "discapacidad"

un otro y un Impasse y diferencia entre cuerpo e imagen del cuerpo. De ese engaño y al mismo tiempo incompletud del sí mismo.

La estructura o registro simbólico que instaura la cadena significante producirá en la relación de y entre los significantes, un resto irrepresentable, impronunciable, inaprensible desde los desfiladeros de la lengua. Ese resto, será el registro de lo real y se interrelaciona con los dos registros: imaginario y simbólico articulando el ternario lacaniano, donde se anuda el deseo y se representará la constitución de sujeto a través del grafo del deseo que Lacan introduce en los Seminario V y VI (LACAN, 1999; 2014). La constitución subjetiva constituye un sujeto escindido, barrado, incompleto y Lacan lo escribirá \$. De la mano con esta mirada, Butler (2012) y Mèlich (1010) pensadores desde y con Levinas conjugan en el término de precariedad la condición constitutiva del ser humano. Levinas (1991 y 2000) filósofo lituano, ha introducido no sólo la voz de la filosofía griega y alemana, sino la voz de Israel. La Tora y el Talmud conversan, dialogan tensionalmente, sin articulación posible, en una producción inaudita que ha impactado y dejado su huella indispensable para abordar la espiritualidad laica desde la Ética de la Fraternidad, la responsabilidad y ser para el otro como única trascendencia posible. Desde una relación entre la hospitalidad y la hostilidad, Derrida (1998 y 2001) invita a no eludir, eliminar o negar la violencia y agresividad en la relación humana, la agresividad no puede ser resuelta, sin embargo se intenta lidiar con ella. Así aportará el término diferancia en esa visión del ser en ruptura entre la hospitalidad y hostilidad y formulará la deconstrucción como respuesta crítica al constructivismo y, sobretodo, mantendrá el debate.

Los autores citados no tienen otra intencionalidad que la de mostrar la apertura a otras miradas y discursos que inauguran otras realidades, otras posibilidades y otras formas de mostrar la complejidad del ser humano en sus circunstancias históricas, en su constitución y formas deconstructivas que inician caminos por inaugurar, senderos y pasajes a la conformación y configuración de realidades que abren un porvenir. 
Esta referencialidad múltiple, como una aurora da a la exploración de un camino de indagación. Ya provee inéditos que introducen otra forma u otras formas de ser y de estar en el mundo con repercusiones en nuestras disciplinas, prácticas y compromiso ético de nuestro pensar y de nuestro hacer. Contiene abordajes desde: a) una episteme de la subjetividad humana producida desde la diferencia, alteridad como exterioridad fundante, diferenciada de la episteme de la modernidad bajo la noción del sujeto como unitario y pensante; b) una concepción de subjetividad como resultante de un acontecer político y social, desde las relaciones plurales, complejas, heterogéneas y contradictorias de y entre los hombres; c) una mirada estructural de la gestión y transformación de los dispositivos de poder, así como una genealogía; d) abordajes de diversos campos disciplinarios de las humanidades.

Esta multi-referencialidad contrasta con los planteamientos iniciales, los cuales han sufrido un agotamiento y los sujetos presentan un desgaste, empobrecimiento y frustración en su sentido existencial. La captura del sujeto bajo la idea de unidad pensante conlleva a la planificación racional hacia la salud y el desarrollo de una conciencia racional con voluntad y libertad para conseguirla; así como un ejercicio de ciudadanía que se distingue como lo adecuado a los cánones de la normalidad. Lo normal como la adecuación de lo esperado, de lo que viene por conformarse. De ahí, imperceptiblemente desliza a lo moralmente bueno y hacer bien las cosas, como deben de ser. Se traduce a un comportamiento legalmente regular y moralmente aceptado.

Implícitamente se realiza una reversión temporal. El sujeto advendrá en lo que es, en función de lo esperado; lo que se espera que sea. Ese que se esperar que sea es la adecuación lo más cercano posible al ideal o ideales. Así el sujeto terminará siendo reconocido o no, en función de lo esperado. Se da un hiato y el sujeto queda siempre suspendido en función del reconocimiento o desconocimiento que se haga de su ser con relación al ideal. 
la constitución o producción de la subjetividad, del sujeto desde el psicoanálisis y del sujeto sujetado al discurso de la "discapacidad"

Este sujeto que piensa su ser, como ser uno, indiviso requiere de una exterioridad para reconocerse. Es otro el que le da el estatuto de ser. Esa exterioridad se asienta en los dispositivos sociales e institucionales que instituyen su individuación.

Ya Canguilhem (2009) y Foucault, M. (1967 y 2007 nos han prevenido del carácter de la normalidad, como normatividad. La normal norma, regula así como genera su propia reversibilidad, su excedente, su resto, lo que sale fuera de ella.

Heidegger señala que es urgente volver a pensar de nuevo todo, quizá se refiera a que podríamos intentar las interrogaciones antes que apresurar las respuestas. Implicaría una disposición a reformular nuestros saberes, instaurar una duda, alertarnos de nuestras certezas, de nuestros modos de ser, pensar y actuar y de la forma y consecuencias éticas de los diversos saberes solucionar los problemas acordes a las formas adecuadas de la vida individual y social.

En el siguiente apartado realizaremos una aproximación a la reformulación del sujeto desde el psicoanálisis.

\section{Del sujeto desde el psicoanálisis}

Las ideas en este apartado son reiterantes más o menos literal, o parafraseadas de otros trabajos que hemos elaborado en el trayecto profesional, vivencial ${ }^{4}$.

El psicoanálisis desde su origen tuvo un rechazo al atentar no sólo contra el canon de sujeto de la conciencia, unitario y pensante sino contra la moralidad existente. Expuso y visibilizó lo que estando ahí, aun así, no existía, no se quería saber de "eso". En Tres Ensayos de una teoría sexual y en el Malestar en la Cultura, Freud (2001, vol 7 y 21) desplegó lo inconscientemente reprimido como movimiento psíquico constituido en el movimiento del lazo social que constituye la cultura, sujetación a la Ley y surgimiento concomitante del deseo como prohibido. Así,

\footnotetext{
${ }^{4}$ En la bibliografía se ponen algunos de nuestros trabajos que dan cuenta o desarrollan las ideas que se expresan en el segundo y tercer recorrido del presente trabajo. El resultado es una inevitable repetición, así sea parafraseada o literal.
} 
mostró la represión de una sexualidad entendida como erotismo y la escisión psíquica del sujeto, su malestar irreversible por ser sujeto de cultura. La teoría sexual freudiana se instaura sobre una desviación de lo biológico y humanamente constituida. Podría señalarse que la deriva del deseo se encuentra en una encrucijada que plantea el erotismo, el vaivén de la vida y la muerte, la continuidad y discontinuidad del ser, el amor, la muerte, la soledad el desamor. En el Malestar de la Cultura la primera interrogación que presenta Freud es ¿por qué el hombre buscando la felicidad no la encuentra? ¿Por qué la angustia, el síntoma y la soledad en el hombre?

Con otras coordenadas epistémicas Lacan reelaborará la teoría freudiana y mantendrá la cuestión de la pulsión, el inconsciente la sexualidad y el deseo.

Freud señala la necesidad de una operación de afirmación y la construcción de una negación en la emergencia de la subjetividad, del sujeto en su división y conflicto. Afirmación, aceptación, rechazo como anulación, negación, ligados a la vida, el placer, la muerte y la destrucción. La afirmación es primero, señala nuestro autor. Se requiere ser afirmado a la existencia. Pudiera realizarse de inmediato la ecuación del Bien como afirmación, y el Mal como muerte o destrucción, violencia y agresividad. Sin embargo, las derivas del deseo bien pueden ir por el mal como su bien. El deseo se aleja de lo moralmente establecido como el bien. El bien puede muy bien equipararse al amor, pero cuidado, también al goce, la destrucción. Tales las derivas del deseo.

Analicemos primero una significación del Bien como ideal. El bien, mi bien es una operatividad del amor, el privilegio que tenemos los seres humanos al ser inaugurados a través de la mirada amorosa materna, del cruce del amor y deseo materno fundante de nuestra subjetividad. Entiéndase que hablamos de función materna más allá del sexo femenino más allá de lo biológico y más allá de lo moralmente establecido: La Mujer como necesariamente madre. Apelamos a la metáfora de la función materna, función de dar a luz, esa luz que es ese llamado a la 
la constitución o producción de la subjetividad, del sujeto desde el psicoanálisis y del sujeto sujetado al discurso de la "discapacidad"

vida, cuidado, acogimiento, pautación y regulación de la vida. La función materna realiza la mediación a la vida. El hijo para ser hijo requiere una llamada, un anhelo de que sea, ese anhelo lo prefigura la función materna, teje los sueños en los meses de espera, quién será, cómo será, qué nombre le pondrá, qué quiere que sea, etc., etc. Desde este origen de proyección del ser por parte de la función materna se establece que el hijo requiere más que biología y su advenimiento o nacimiento lo constituye esa función materna de anhelarlo como un ser de y en copertenencia en comunidad, en cultura. Necesita para ser humano un llamado, un alguien que lo espere, sueñe y tenga ya una ficción y un porvenir imaginado. Requiere quien realice ese acto inaugural, quien lo invista con su anhelo, le proyecte un guión, una historia. La función materna y la función paterna proyectan los sueños en sus hijos, esperan que ellos realicen lo que ellos no pudieron, que tengan lo que ellos no tuvieron, es decir que desean que sus hijos efectúen lo que a ellos les fue negado, que concluyan la realización de su existencia. Por ello Freud planteó al hijo como deriva del narcisismo paterno. Este planteamiento ya indica la constitución del sujeto desde una exterioridad.

Eso que llamamos amor, es una producción, produce subjetividad y requiere lo relacional. Sólo se da entre seres de cultura. Como señala Lacan, la relación humana más paradigmática es el amor, es la relación más radical, más compleja y más profunda de los seres humanos (LACAN, 1987) ${ }^{5}$. En toda relación amorosa el que se enamora da, es decir el amante da y da y da, sin embargo da algo del orden de lo que no tiene. Lo que tiene es deseo, sin embargo su deseo es deseo del otro o por el otro y con ello configura su identidad. En dicha relación del deseo del otro, se expresa una falta implícita, una carencia ya que el deseo es del orden de exterioridad y el amado hace señuelo de ser eso que falta, el amado se mantiene en ese lugar en la medida que cubre, que vela la falta del amante, ya que si bien el amante da, ese dar es porque no se tiene, se busca en el otro que realice algo del orden de lo irrealizable, algo

\footnotetext{
${ }^{5}$ Lacan, J. (1987) Seminario 11. Los cuatro conceptos fundamentales del psicoanálisis. Buenos Aires: Paidós.
} 
imposible, por eso tarde o temprano, la complejidad del amor es tan radical que lleva siempre al punto límite, del más allá. Profundamente lo que se anhela sólo hace señuelo a través del otro, que el sujeto amado no posee porque no es. Tarde o temprano, ese no ser, desamarra el ideal y convoca a la agresión, al enojo por el no cumplimiento de deseo. Tal pareciera que esta relación finalmente lleva al incumplimiento. El deseo es incumplible a menos de llevarlo a la última presencia, a lo insondable, al abismo del tiempo, al infinito, al no ser.

La cultura abre la brecha al orden biológico. La cultura regula las relaciones a través de prohibiciones y permisiones, ello desencaja lo biológico. El orden biológico nos encaja en la vida y la sobrevivencia en nuestra especie, opera por la sexualidad: la reproducción a través de un femenino y un masculino. Cada uno de la especie en su particularidad muere. La vida va aparejada con la muerte y la sexualidad preserva la especie. Sobre este orden biológico la cultura reguló las relaciones e instauró las formas que el hombre se ha venido dando en el intercambio entre ellos acorde a las reglas fundamentales del parentesco que no se rigen por lo biológico. La cultura es ya operar y alterar lo biológico bajo ciertas pautas que dan paso a la regulación del intercambio y con ello a las diversas formas culturales a través de la historia. Un efecto de la regulación implica la dupla: prohibir-permitir que es la regulación. Al instaurar la regulación se instala un dique, un surco orientador, un límite que opera como frontera, prohibición, impedimento. La regulación ya implica prohibición. Un binarismo que abre y cierra, modula, regula, permite, impide. Un No y un $\mathrm{Si}$, un rechazo o aceptación; malo o bueno. Reglas de relación, prohibición del incesto, lo implícitamente vetado. El intercambio regulado realiza una exogamia y una endogamia, un adentro y un afuera, un semejante, un diferente. En este binarismo, la prohibición inaugura algo del orden de lo humano: el deseo. La ley instaura su propia negación, instala también la transgresión. Eso que se prohíbe, eso mismo atrae. La regulación instaura el acto de prohibición y con ella el deseo. Se desea justo lo vetado, lo prohibido, lo negado. El sujeto deniega la prohibición. 
la constitución o producción de la subjetividad, del sujeto desde el psicoanálisis y del sujeto sujetado al discurso de la "discapacidad"

La ley al limitar, restringir, ejerce una presión, una pulsación que empuja al sujeto a encarnar en el cuerpo huellas, una escritura enigmática que suscita búsqueda de desciframiento. El cuerpo se inviste sobre el orden biológico. A partir de la cultura, la regulación altera el orden biológico de la necesidad y satisfacción. El hambre, la sed, la sexualidad y un sinfín de actividades entran en el circuito de la regulación. Entre el circuito de la necesidad y satisfacción biológica, se introduce la demanda. Los padres regulan algunas necesidades como la alimentación, defecación, sueño, etc. Así por ejemplo la necesidad alimenticia se ve transformado por la demanda de los padres: poco a poco se va sujetando a horarios, se eligen ciertos alimentos, horarios de sueño, horarios que se regulan, alimentación, el control de esfínteres, etc. Estas demandas, peticiones, requerimientos inauguran las pautas culturales y le dan sustancia al registro cultural simbólico. Y ahí, en este montaje entre el orden biológico y el cultural, algo se instaura: el deseo, que resulta más allá de la demanda. Así tenemos circuitos en la relación entre los sujetos en donde se instala el desencuentro entre necesidad y demanda por la producción del deseo. El juego del deseo es el juego amoroso.

La relación fundante del amor realiza el pase al naciente. Pasaje de lo biológico a la subjetividad a través de la envoltura de la demanda amorosa, ese efecto de intersubjetividad posibilitada por un orden cultural que desviado de lo biológico lo instaura en un orden de regulación cultural simbólico, lo introduce en la dialéctica del deseo, le solicita, le demanda algo al viviente que va más allá de la demanda. Ese más allá es el juego del deseo convocante. El proceso de subjetivación implica la respuesta o intento de la respuesta a la demanda y hallazgo de que el otro no sabe muy bien que demanda, que hay un más allá al que se le pide que él responda. Él tiene que responder al deseo del otro. Responderá inaugurando su deseo a partir del deseo del otro.

El circuito del amor implica un amante y un amado, el amante busca en el amado su bien, lo instala ahí, como su objeto amoroso y éste se identificará con ese 
bien, es el bien amado. Sin embargo como todo sujeto colocado como bien, tiene que sostener lo insostenible y por tanto imposible, caerá del lugar de amado, a menos que no responda a la demanda, preserve el "no", porque ahí el amante insistirá, ya que la resistencia del amado mantendrá en vilo su deseo, porque en cuanto el amado complace la demanda, se encontrará con la distancia del deseo, el cumplimiento de la demanda no es como en el circuito de la necesidad-satisfacción. Ya que dijimos que el operativo de la prohibición instaurará algo del orden de lo imposible, la demanda es un velo que oculta y articula el objeto del deseo. Si la demanda pasa a ser cumplida, se devela el señuelo, el amado deja de ser amada, cae como su bien ya que al cumplirse la demanda, se encontrará la distancia, la instauración de nuevo de la insatisfacción, desazón. De nuevo el rugido del deseo. Estos tiempos modernos nos instalan en una obsesión por la satisfacción, que se transforman de inmediato si se satisfacen en satisfacción y quizá por ello Slotter diga que los tiempos actuales no son del orden del deseo sino de la fatiga. En una entrevista sobre el estatus de la utopía en la actualidad, que le realiza Alcoberro (2016) a Slotter, éste responde: "Nuestro tema principal no es el deseo, es la fatiga. Dicho de otra manera, la finitud del deseo deviene nuestra evidencia primera". Si bien Slotter no refiere al deseo tal como se estipula en psicoanálisis, sino en su uso común, como deseo de algo, un objeto, lo que implicaría en psicoanálisis la demanda. Su cumplimiento lleva a la fatiga. La compulsión a la adquisición de mercancías ofrecida siempre como objeto de satisfacción lleva a la fatiga, ya que el objeto de la demanda siempre es señuelo de otra cosa, del orden del deseo intangible, por ello su adquisición siempre produce mayor insatisfacción y a mayor compra mayor insatisfacción, de ahí la fatiga.

Así, el amante se mantiene en posición de amante en tanto el amado se escabulla a su demanda. Si le da cumplimiento, cae el amante al desengaño ya que el amado al responder a la demanda se aleja del deseo del amante, ya que la satisfacción no es cumplimiento de deseo. El amante hace señuelo al amado ya que mantiene en suspenso la satisfacción, por tanto la búsqueda hacia el objeto se mantiene en tanto no 
la constitución o producción de la subjetividad, del sujeto desde el psicoanálisis y del sujeto sujetado al discurso de la "discapacidad"

responde a la incógnita del deseo del amado. El deseo se torna intangible, no es del orden de un objeto tangible, tiene un estatuto misterioso, enigmático en donde se cifra nuestro ser, ser en cuanto no se sabe. Por ello el otro es soporte de la ilusión amorosa, el otro sabe de nuestro ser, de esa incógnita de ser.

Así nuestra constitución subjetiva adviene en la medida que somos investidos y valorados como un representante idealizado del cubrimiento de la falta del otro. Descubrimos muy pronto nuestra caída de dicho lugar, y procuraremos de nuevo instalarnos en ese lugar de deseo aunque en cada repetición volvamos a experimentar la caída.

Toda constitución subjetiva implica que todo naciente se torne existente para el otro. El naciente humano ha sido solicitado a ocupar un lugar, un sentido, una significación mucho antes de su entrada biológica al mundo. Diríamos que la cultura predetermina las funciones, lugares, posiciones de los sujetos y regula sus relaciones. Por ello no puede entenderse al sujeto como individuo, y la sociedad como la conjunción de individuos. Por principio no existe el hombre, ya que un hombre no puede vivir sino en relación con otros hombres. Los niños ferales muestran la ausencia de la intervención de lo humano. En su vida han intervenido animales y se han constituido desde otras coordenadas, biológicas. Por ello los niños ferales convocan al gran enigma del origen. Si hay enigma del origen es porque hay un punto cero, un antes de y después de que constituye al ser, ese antes y ese después no es una temporalidad sucesiva. Se funda en la misma operatividad de la intervención cultural vía el lenguaje. La pregunta por el origen, preocupación por el fin sólo se adquiere ante la experiencia de la angustia, de la ausencia, de la finitud.

Inicio y término. Las dimensiones temporal y espacial se inauguran al inscribirnos como humanos. El origen, de dónde venimos, el antes; remite a una incógnita del origen, enigma y tabú del origen, la pregunta que realiza el niño no tiene respuesta posible, por más que se esfuerce en dar una, el niño lanzará la siguiente pregunta. Se configura un mito, así sea el de la semillita que papá pone en 
mamá ya que por más explicación que se intente dar, el niño no lo satisface. Quizá porque sabe en algún lugar, que el adulto algo no sabe. Y, ¿cómo se puede saber de la vida y de la muerte? Ante ellos sólo los mitos, las creencias, la fe. La incertitud ante lo finito-infinito. La relevancia del linaje ocupa su lugar, la herencia, los dones, los deberes y haberes. ¿Quién nos ha dado qué? ¿Qué deuda se instala? ¿De dónde vengo ¿Quién me antecedió? ¿Qué me fue donado? ¿A quién le debo? ¿A qué me debo?

Estamos ante la posibilidad de abordar la subjetividad no desde el desarrollo individual, (abordaje que hacen las diversas teorías psicológicas, aquellas que tratan al individuo como objeto de estudio), sino como un sujeto, no un ser pensante. Un existente advenido desde la preexistencia cultural e histórica y los padres que se encargan de su constitución a través del desfiladero de su deseo. Lo acogen y le invisten su visión de mundo a través de las relaciones intersubjetivas que conforman su núcleo constituyente, su estructura o andamiaje y la deriva de su deseo en el marco del deseo de sus otros, en su apego o pegoteo a esas representaciones o exigencias de representación valoradas como supremacía. El ser humano constituyente sufre como ser de búsqueda entre el reconocimiento y el desventurado desencuentro. Ante esta complejidad de advenimiento del sujeto, se instala la pregunta: ¿Y la constitución subjetiva de la persona con discapacidad? Pasemos al tercer recorrido

\section{Sujeto sujetado al discurso de la "discapacidad"}

Los dos recorridos han apuntalado un andar, una incursión a deconstruir el concepto de discapacidad, tarea que no puede realizarse sin considerar su adscripción a la normalidad.

Obliga la interrogación, ¿de dónde viene el término discapacidad? Construir su origen es dar cuenta de la historicidad. Historicidad no es un recuento ni de fechas, ni ir a su búsqueda encontrándola desde el significado del presente. De ahí 
la constitución o producción de la subjetividad, del sujeto desde el psicoanálisis y del sujeto sujetado al discurso de la "discapacidad"

que la historia que tenemos es un recorrido de un pasado ya pasado y encontrar en él lo que se desea encontrar.

Corresponde un andar a partir de la interrogación de la exterioridad de la discapacidad. Es decir, ¿qué exterioridad hizo posible la discapacidad? ¿Cuáles fueron las condiciones históricas que dieron emergencia, visibilidad y discursividad a lo que actualmente se considera como discapacidad? ¿Cómo se inscribió una subjetividad desde la noción de discapacidad? Ya el punto dos permite ver la condición de exterioridad para dar lugar a la subjetividad. La identidad del sujeto tiene como punto de partida una otredad, una alteridad, una exterioridad que pone en movimiento la constitución subjetiva. Explicitamos las funciones, lugares y posiciones que la cultura establece como una matriz simbólica, a la adscripción del sujeto por venir, advendrá conformándose a dicha matriz. La matriz simbólica conforma y se conforma de saberes que se van legitimando.

¿Cómo se constituye un ser en donde su cultura tiene las funciones demarcadas y delimitadas sobre las representaciones del sujeto. Sujeto de reconocimiento, libertad, éxito, progreso, valorando su progresividad en el mundo, con los otros. Estas representaciones se encuentran instaladas, afianzadas, reiteradas, legitimadas y se reproducen sin mayor cuestionamiento. De ello dimos cuenta en el primer recorrido. Suelen pasar por saberes legitimados. De los saberes que legitiman tales representaciones, las teorías del desarrollo psicológico prescriben instrumentos para medir el nivel de progreso o proceso de desarrollo que tienen los sujetos considerados con dificultades. Se ha olvidado el irreductible contexto histórico que hizo posible la emergencia de los instrumentos acordes a una visión de mundo. Se ha descontextualizado, se ha elevado como teoría sin relación con sus condiciones emergentes y por ello se encuentra fetichizada como verdad. Es el pre-juicio al que refiere Arendt (2001), lo que va antes del juicio, ese pre que da cuenta de la realidad e impide la acción del pensar heideggeriano. 
Por otro lado, la sociedad moderna ha erigido el dinero como el significante del Bien y ha elevado al sujeto entendido en su individuación como resultado de su esfuerzo y su proceso de desarrollo. El Bien dinero como significante tiene como piso la relación contractual como instrumento del desarrollo económico. La relación contractual se basa en un convenio que estipula los derechos y obligaciones en ambas partes (el que contrata, patrón o empleador y el contratado, empleado o trabajador). El trabajo se ha convertido como el eje por el cual el sujeto afianza su existencia, si no trabaja es como si no tuviera ni lugar ni posibilidad de acceder a nada en el mundo, le es vedada la vida. El trabajo tiene dicho estatuto por la remuneración que se obtiene a través de él: el salario. Esta relación permite la circulación del dinero y regula los múltiples intercambios. Se tiene acceso a mayores bienes en la medida que se tiene más poder adquisitivo vía el dinero. Lo que Marx desmontó o visibilizó fue lo oculto del intercambio que es la plusvalía, el plus que el contratante obtiene del producto del trabajo del contratado y que es el factor de acumulación del capital, de la riqueza. La acumulación no se refleja en el contratante, en tanto que se extrae del trabajo del contratado y las derivaciones de la circulación del producto del trabajo. Este es el origen de la desigualdad económica del dispositivo del capitalismo. Dicha desigualdad va posicionando a los sujetos acorde a la posibilidad de acceder a los bienes. A mayor remuneración mayor acceso a bienes, mayor envergadura del sujeto en la escala social. Así la desigualdad no se genera por los atributos de los sujetos sino en las posibilidades de acceder a los bienes. La vida social valora conforme se obtienen más bienes y a la calidad de los mismos. Ante esta situación, Butler (2012, p. 50) resalta:

[...] la política necesita comprender la precariedad como una condición precaria compartida; y la precariedad como la condición políticamente inducida que negaría una igual exposición mediante una distribución radicalmente desigual de la riqueza y unas maneras diferenciales de exponer a ciertas poblaciones, conceptualizadas desde el punto de racial y nacional, a una mayor violencia.

Nos parece relevante esta condición de precariedad inducida. De alguna manera es algo que se sabe. Los que ganan más, tienen más acceso a bienes. Se 
la constitución o producción de la subjetividad, del sujeto desde el psicoanálisis y del sujeto sujetado al discurso de la "discapacidad"

considera obvio. Sin embargo, ocurre como con el plusvalor, se invisibilizan los procesos complejos, múltiples y heterogéneos que van constituyéndose aparejados, concomitantes a esta cadena económica. Esto va configurando dispositivos que van regulando una vida social con contrastes y efectos de diferenciación, separación, discriminación e indiferencia, en la medida que se conforman los de afirmación, reconocimiento confirmación. Así para el sujeto con discapacidad le es vedada la vida social desde la imposibilidad de acceder al trabajo ya que no concuerda con los cánones de la relación contractual. Es la estructura de la relación productiva y no la denominada discapacidad como atributo la que impide el acceso al medio laboral.

Aquí cobra relevancia la historicidad planteada por Benjamin. Se señaló en la primera parte: el pasado en tanto porvenir. La disolución de la historia mantiene la reproducción del futuro anterior del pasado, es decir el olvido de la génesis, mantiene y produce una metástasis anunciada ya que en su aparente cambio anuncia la exacerbación de lo que se prefiguró en el futuro anterior que constituye nuestro presente de lo que vendría a ser bajo figuras que han deslizado la situación de mantenimiento, reproducción bajo otras figuras. En este mismo proceso es innegable que al deslizar en otras figuras, se produzcan acontecimientos inesperados y ahí radica el cambio y la transformación. Esto amerita un estudio a profundidad. Con todo será la guía para repensar la discapacidad desde esta perspectiva de historicidad.

La individuación como pre-juicio se mantiene vigente, como una realidad y se invisibiliza que ha sido producida. El individuo es considerado como el agente causa de su condición de vida y remite a una situación personal. Si el sujeto tiene bienes o no, se le adjudica a un logro personal, a sus características, y a sus circunstancias. Es decir se le debe al individuo. Así cada sujeto es lo que es. ¿Pero qué es? Ser o no Ser, El sujeto es pobre, el sujeto tiene una discapacidad que es de él, el sujeto es negro, o chino, indígena, el sujeto es musulmán, el sujeto es una mujer, es gay, etc. La conformación de colectivos de cada uno de estos seres, se ha venido conformado por 
su ser vulnerables, su ser como es, es vulnerable y tiene efectos de discriminación, exclusión, abandono, violencia, indiferencia, etc. En la transmudación a colectivo surgieron múltiples acciones y procesos. $\mathrm{Y}$ cada grupo ha gestado un movimiento hacia los derechos humanos clamando por sus derechos, considerando cada uno su condición. Actualmente tenemos tantos movimientos como grupos identificados colectivamente en esta condición y se está generando una proliferación de ellos. Cada uno de estos grupos tiene su historia y también su incidencia en las respuestas que se han dado desde las diversas instancias instituciones. ¿Cómo ha respondido el sector salud?, ¿el sector educativo? ¿el jurídico, ¿el cultural? ¿La familia? ¿Qué respuestas se han dado?

Desde el sector académico, y de la investigación estos grupos se encuentran constituidos en un campo de saberes y especialistas sobre las diversas condiciones de vulnerabilidad, cada uno de manera separada. ¿Cómo se articulan a lo interno y externo de cada uno de estos ámbitos? Esta fragmentación y desarticulación entre los grupos se justifica por su propia condición. Los hace completamente diferentes uno a otro. Se consideran ajenos unos de otros en sus luchas, estudios, temas, abordajes.

Justo aquí cobra relevancia la pregunta por la historia olvidada pero presente (como futuro anterior). Al dar por sentado, como natural que el sujeto es por su condición de ser, se olvida cómo se da el proceso por el cual el sujeto adviene a ser eso que es. Es decir, el olvido del ser en su condición de siendo, de advenir en lo que ha sido anunciado para su enunciación. Esa exterioridad constituyente de su ser.

Primeramente quería expresar esta condición de historicidad olvidada para toda una configuración de grupos considerados vulnerables que no visibiliza la historia común (que no igual), que los atraviesa y constituye. Demos paso ahora al grupo que también, bajo el olvido de su historia, ha resultado en un sujeto de enunciación: Ser sujeto con discapacidad.

Si la premisa de este trabajo es la necesaria consideración histórica, la pregunta: ¿cuáles fueron las condiciones exteriores que dieron lugar a la emergencia 
la constitución o producción de la subjetividad, del sujeto desde el psicoanálisis y del sujeto sujetado al discurso de la "discapacidad"

de la "discapacidad" es obligatoria. Dar cuenta o deconstruir cómo ha sido dada la condición de ser sujeto sujetado al enunciado de discapacidad, esa es una tarea por realizar. Un intento ha sido elaborado en Jacobo. (2008; 2012; 2013).

Al no preguntarse por la conformación de la condición del ser, ser ese con discapacidad adjudica su vulnerabilidad a causas físicas: por su condición física. Así encontramos a las discapacidades consideradas como: ceguera, sordera, trastornos de motricidad, discapacidad intelectual, etc.

Retomar la precariedad inducida, implica ver cómo estas características físicas han sido simbolizadas o adquirido una significación de discapacidad en los tiempos modernos, no así en otras épocas históricas. Veamos como la actual distribución desigual de la riqueza ocasiona un plusvalor de resta real y simbólica. Un parto en condiciones rurales que no cuenta con equipo material y humano necesario, interrumpe la posibilidad de salvar una vida. Es la falta de equipo, el incumplimiento de un estado en las poblaciones más desfavorecidas lo que provoca los altos índices de infanticidio y desnutrición. La vida biológica es intervenida por la cultura, según se cuente o no con los dispositivos para ofrecer las condiciones y posibilidades para salvar la vida del niño, de la madre, o de ambos. La situación de alcoholismo es lo mismo. ¿es del sujeto o el sujeto resulta afectado por los procesos de vida cultural? Se demuestra en los estudios estadísticos de como en ciertas épocas el índice sube o baja, según las circunstancias históricas, políticas o económicas. Que determinados sujetos y no otros resulten afectados, es digno de investigar, cerrarlo en una afirmación de individuación sólo hace recaer la responsabilidad o explicación en el sujeto particular. Así también pasa con el enunciado de discapacidad. Éste es asignado desde una exterioridad al sujeto y tanto él como la familia resultarán signados y en reflejo, se produce una ecuación especular en el sujeto que adquirirá y conformará junto con su familia, una identidad de discapacidad. La enunciación, asignación y designación pasa invisibilizada, la normalidad toma el mando y genera su resto: el sujeto está en falta, así la norma, norma. 
La normalidad de este proceso de diferenciación a unos y otros se instala y se obscurece. Las carencias y precariedad son generadas desde las condicionantes del sistema, y no desde los atributos del sujeto. Por ello el planteamiento de la precariedad inducida de Butler es esencial. El proceso de constitución de los prejuicios específicos de la modernidad resultan incuestionables se mantienen: a) noción de individualidad, como el sujeto unitario, consiente, con libertad de desarrollar su plenitud y amo de su destino con sólo proponérselo; b) una noción de trabajo basado en el esfuerzo individual y que invisibiliza un plusvalor como el dispositivo de la desigualdad y, c) una noción de normalidad como la vida que se aspira a conseguir, acorde a las representaciones derivadas del plusvalor y de la individuación. Quien tiene más de los bienes es más. Y se aspira a ese lugar de más. Esta espiral ascendente enmarca perfectamente con la producción de mercancías como bienes y pauta la forma o norma de vida. La aspiración a lo normal.

Estos tres grandes discursos ofrecen los espejos de conformación de identidad y reconocimiento para cada sujeto que ingresa a esta cultura. Toda representación que salga fuera, esté en oposición o no encaje, marca un destino desfavorable de vida. Así entonces veamos cómo esta misma cultura ofrece espejos siniestros y peor aún, los sujetos se adscriben a ellos.

La representación de individuación hegemónica y predominante impide pensar de dónde viene su constitución. Rompe con el origen exterior de evocación a la existencia. Así se preserva esa ficción de individuación, unidad imaginaria a toda costa. Pensar cómo conforma un sujeto denominado con discapacidad su identidad, es atrevernos a pensar lo impensado. El significante de discapacidad no ofrece de entrada sino un quebranto identitario, nadie quisiera verse reflejado ahí. En la discapacidad.

Bechara (1913) en su libro: Familia y Discapacidad recoge y articula las voces tan olvidadas de los miembros familiares. Nos señala que el nacimiento del hijo no es motivo de trauma, sino que el trauma se inaugura con la sentencia que anuncia el 
la constitución o producción de la subjetividad, del sujeto desde el psicoanálisis y del sujeto sujetado al discurso de la "discapacidad"

médico a través del diagnóstico. El Diagnóstico médico se transforma en algo siniestro para el padre y la madre, una sentencia fatídica, ya que no inaugura ni a los padres ni al niño un porvenir sino un cierre prematuro a un proyecto de vida.

La cadena de la salud, la educación, y los pre-juicios mantiene y fomentan la imagen de "deficiencia" y "discapacidad" como algo natural, como un atributo "natural" del sujeto, sustancial. Sería tanto como decir: la discapacidad existe, es "algo" real, óntico. Por nuestra parte mantenemos su cuestionamiento y lo planteamos como resultante del orden de lo humano y el sujeto resulta afectado e identificado con la imagen, o significación. Compete al acontecimiento, lo que acontece en el hombre. Y el orden del acontecer de lo humano tiene que ver con la palabra, con los efectos de la palabra en el hombre, con la producción, creación y generación de sentidos y significados que a lo largo de la historia se han producido y afectado el orden de las relaciones de los hombres entre sí.

La palabra brinda una posibilidad de ser, ser de existencia. Por ello Heidegger puede darle la función de creación a la palabra, de acción, de obra, de producción de "las relaciones fundamentales características de cierto modo del ser humano en una época determinada". (LACAN, 2009, p. 18).

Por ello quizá Heidegger postulaba la infinita tarea de descifrar, de que ningún signo ha agotado el sentido del hombre, el hombre signo indescifrado, inconcluso. Con ello querría decir que si hay que descifrar, es que hay de por medio un algo, símbolo, representación, notación, enunciado. Algo se enuncia y al enunciarse de produce una enunciación. El sujeto se enuncia, y en ese enunciado que se dice de él, quién o qué ha producido su enunciación? ¿En qué historia se ha inscrito su enunciación? La acción histórica es productora de un tiempo particular que articula pasado, presente y futuro. Será la historia, como dice Lacan una lectura: “...leer en la serie de mutaciones del hombre el progreso de los signos con los que constituye su historia." (LACAN, 1987, p.160). 
Lo anterior nos invita a tomar al pie de la letra la discapacidad como signo, como un mito constituido. Entre los dispositivos que se conjuntan para su constitución el diagnóstico, herramienta base de la intervención en los diversos ámbitos: salud, educación; dictamina, encamina y realiza la operación de adquisición de una identidad en el sujeto a través de esta imagen de diagnóstico. Espejo que permite el advenimiento de un sujeto en falta, enunciado como con discapacidad, así al nombrarse como tal, ¿qué tanto habla él? ¿qué tanto su enunciado no viene de una enunciación anterior, preexistente, exterior?

¿No es acaso la normalidad una enunciación de Ideal y que posicionará al sujeto en falta? Por ello resulta preeminente $\mathrm{y}$ fundamental desmontar esta especularidad, desestructurar este inconsciente, esta realidad pulsionante del sujeto que lo convoca a situarse como tal, como persona "con discapacidad".

La discapacidad adviene un resto, una falta, un excedente y resto asignado desde una posición de completud, de valor y de lo que se representa como Ideal, como lo que no falta, como punto final? Sin duda el Ideal apertura la falta, da lugar a la falta ya que el ideal es del orden de lo aspiracional debido al reconocimiento de que se carece, si no, no se aspiraría. El ideal requiere para sostener su lugar, el lugar de la falta y la carencia.

Ante el ideal, que suele ser representado por personas y objetos, el sujeto se encuentra con su falta, su ser en falta? Ante la falta se puede generar una resistencia, una oposición, una violencia, una alteridad? ¿De qué se trata sino de una imposibilidad de relación identitaria con una imagen emblemática de ideal y completud? Dicho Ideal, ¿no nos confronta con la carencia, la nuestra? Siempre y cuando reconozcamos y hagamos nuestro el Ideal, sin embargo lo que no vemos es cómo ha sido constituido dicho ideal al cuál se nos demanda ser o alcanzar y nos contrasta con la imposibilidad de alcanzarlo.

¿No es acaso sosteniendo, aceptando y reconociendo el concepto de la normalidad como lo dado, no anticipa lo no dado, al mismo tiempo, de lo que falta 
la constitución o producción de la subjetividad, del sujeto desde el psicoanálisis y del sujeto sujetado al discurso de la "discapacidad"

para llegar. ¿No es la evaluación el parámetro de lo alcanzado en relación a lo esperado? No es la normalidad el parámetro de la condición de salud, desarrollo, trabajo, individuación? ¿no es así como nos hacemos artífices, cómplices, sostenedores y reproductores de la normalidad como pre-juicio? Pre-juicios que conllevan representaciones visuales, morales, y que determinan la forma como nos relacionamos entre los hombres? Esto genera la diferenciación de los lugares, y posiciones de la subjetividad, de reconocimiento, aceptación y semejanza o de desconocimiento, indiferencia, de inclusión o de exclusión.

De la constatación de la falta como alergia, como inasimilable, indeseable e inadmisible se da paso a trastocarla en violencia, mitigar ese abismo al que nos arroja. Si no se da la pauta de decontruir los lugares producidos desde las condicionantes de exterioridad, las visiones de mundo, los ideales y sus vacíos, se puede quedar en un atrapamiento especular de rechazar al otro que representa el ideal para ocupar dicho lugar. Se rechaza al otro que representa el ideal, pero se glorifica la representación e ideal mismo.

Sostener los conceptos sin interrogación alguna de su constitución, de su origen; sin atender su irreductible condición histórica de la que surgieron, va en contrasentido del Pensar heideggeriano. El pensar se gesta de la duda, de la interrogación que lanza a la búsqueda, a la indagación, y dicho proceso es el que hace el camino autoformativo. ¿No es acaso la posición crítica tarea misma del pensamiento? No es la investigación eso que arranca desde la interrogación? ¿No es acaso la tarea formativa poner al estudiante a la resolución de una interrogación, de su búsqueda.

Suspender la interrogación y la incógnita y dar por sentado el conocimiento sin la participación interrogativa de los sujeto nos lleva a la posición paralizante y reproductiva del sometimiento de todo orden. A la afirmación de que el mundo es como es, y otorgarle un estatuto de naturalidad. Una naturalidad que no tiene nada de naturaleza. 
El pensar nos consigna a la deconstruccion de la institucionalización de la normalidad, conlleva a su relatividad, a su deposición como ideal al historizar sus construcción y entender como esa construcción anticipó el ideal con el que vivimos en el presente. Por ello nuestro presente resulta un futuro anunciado del pasado, es el ayer sin duda el que nos configuró en un futuro anterior que es nuestro presente. El camino a la transformación es dar cuenta de nuestro presente como anticipación del pasado para que iluminándolo podamos realizar un pasaje al acontecimiento, a dar el paso a lo inesperado, al acontecimiento, a la experiencia. Es un pasaje a lo inesperado.

Quizá el sentido de la experiencia es justamente una búsqueda contraria a la aspiración del ideal, resulta más bien una apuesta, un riesgo, una aventura, ir hacia el encuentro con lo inesperado, del otro y de mi mismo. Es la incursión y aceptación de la incógnita y suspensión de la certeza y de la confirmación y reafirmación de lo que es. En tanto, la asunción de la falta, del no todo mantiene el arcano, el secreto, lo real no apalabrado, lo fuera del sentido. Quizá ahí opera la creatividad, hacer obra, es producir lo no visto. En el ir realizando la obra, en el andar andando que surge el camino. Es ir hacia la búsqueda lo que apertura un posible porvenir que se desconoce porque se está por producir en el acontecimiento.

\section{Las emergentes prácticas sociales}

A partir de esta idea de apertura y de interrogacion nos ha llevado a las prácticas sociales e ir constantando un andar andando, y es en ese andar que se está contruyendo un camino, una obra, una creación, unas nuevas formas de ser, de estar en el mundo.

Quizá la pregunta sería: ¿por qué tendrían que ser una discapacidad y no otra forma de ser y estar en el mundo, de habitarlo, de representarlo, otra manera de vivir en el mundo? ¿Podríamos pensar la ceguera, la sordera diferente a la identidad susbtancialista de discapacidad? Por ejemplo en la ceguera, el nervio óptico está interrumpido, algo ocurrió que no funciona, sea congénito o adquirido. Por dicha 
la constitución o producción de la subjetividad, del sujeto desde el psicoanálisis y del sujeto sujetado al discurso de la "discapacidad"

interrupción es entonces imposible darse un lugar en el mundo más allá que como persona con discapacidad? Las prácticas nos muestran que ya lo han hecho, probado, comprobado. Para la sordera, ¿la no posibilidad de recibir las señales fonéticas impide ocupar un lugar en el mundo, habitarlo y no como persona con discapacidad? ¿Es la no posibilidad de un órgano o función orgánica lo que constituye la discapacidad? ¿No será más bien un pasaje, un movimiento, de que ante lo que se espera, o lo que viene inesperadamente, produce un efecto de pérdida, a priori o a posteriori? ¿Puede tener un efecto traumático en mayor o menor grado? ¿Qué hace que una condición particular trastoque al sujeto, sus relaciones más cercanas y a su entorno en un sentimiento, idea o representación de falta, de duelo, de pesar, de negatividad y que hace que no lo toque ni adscriba en la negatividad? Quizá la falta en lo orgánico pueda tramitarse para que no tramite en discapacidad.

Cómo resistirse a que la falte se substancialice? Quizá provocando la plasticidad de la significación o bien su subversión. Por ejemplo basta buscar en internet el programa de radio "La Pirinola gira en la Radio" para constatar cómo los jóvenes con Síndrome Down se han identificado con el nombre de Síndrome Down. Sin embargo, en el proceso de darse un lugar en el mundo en el hacer uso y manejo de los medios, han producido un cambio en su significación, su trabajo, su posición, su actividad y su posicionamiento ha transformado el sentido y significado dado de la discapacidad y la han de-substancializado. Han configurado en su práctica una subversión al signo Síndrome Down y se han conformado orgullosamente con dicho nombre pero trastocando con su hacer el significado atribuido socialmente.

Por ejemplo lo que Capurro (2004) nos señala de Foucault con respecto al movimiento de los que se han denominado queers, por un lado retoman un significado peyorativo y lo reivindican como una posibilidad de ser otro que como lo normal lo determina. Así todos los atributos de la discapacidad han sido puestos en jaque por los propios sujetos siempre en relación con otros sujetos que se han echado 
a andar y han construido caminos. Por ello retomamos el señalamiento de Capurro (2004).

Por lo tanto, no se trata de reformular una nueva clasificación que los integre en la normalidad, logro que políticamente no es desdeñable, sino que su propuesta va más allá del campo político y apunta a una estética de la existencia, a un cierto estilo de vida que ha de ser inventado. ¿Qué relaciones pueden ser establecidas, inventadas, multiplicadas, moduladas, a través de la homosexualidad. El problema no es el de descubrir en sí mismo la verdad de su sexo, sino más bien de utilizar la propia sexualidad para lograr una multiplicidad de relaciones" ...la pregunta ya no es ¿quiénes somos? $\mathrm{Ni}$, ¿cuál es el sexo verdadero, al contrario se trata de escapar a esas preguntas tramposas mediante esta otra ¿Qué hacemos de nosotros mismos? Ese horizonte pragmático es a la vez estético, una invitación a desplegar en la vida una cierta inventiva, un savoir faire, un estilo en donde la verdad queda colocada en relación a un decir tramado con una vida en construcción (190191).

Y como Galileo decía: Y sin embargo se mueve, se da el acontecimiento. Algunos sujetos han logrado darse otro lugar, conformar otro espejo, para que sean vistos ahora por los otros y los vean, los miren como lo que no han querido verlos, se han resistido, y han apostado por devolver una especularidad que nos convoca a mirarlos desde otra identidad, nos muestran sus formas alternas de ser y estar en el mundo, su pluralidad del ser y con ello conquistado su lugar, su propio lugar en el mundo. Han realizado la experiencia del acontecimiento, han hecho producir y visibilizarlos desde su manera de ser singular. Desmienten el significado de discapacidad. ¿En dónde están esos rebeldes del signo de discapacidad? Sin duda en las formas de expresión del arte, prioritariamente, pero no tan solo. Hemos dado cuenta de ello en varios trabajos (Jacobo, 2010, 2015).

En estos trabajos se documentan las obras de teatro con actores sordos, Seña y Verbo es un ejemplo para constatarlo; las esculturas o exposiciones de fotografías de artistas ciegos como Pedro Miranda y Gerardo Nigenda entre muchos otros, son ejemplo de ello. Asimismo los videos de los recorridos que realizan los escaladores ciegos de Hidalgo por ejemplo para mostrar sus formas de habitar el mundo. Verlos jugar fútbol y enseñarles a sus hijos. (JACOBO, 2015). 
la constitución o producción de la subjetividad, del sujeto desde el psicoanálisis y del sujeto sujetado al discurso de la "discapacidad"

Este documento invita abrir la mirada, ir a su encuentro, es cuestión de la inauguración de otra relación y constatar el acontecer que se está produciendo, verlos en sus formas de ser para que las constatemos en nuestro alrededor. La investigación de las formas de ser alternas está por escribirse, signarse, y con ello hacer discurso de ellas. Nos espera dicha tarea, ese ponernos a andar.

\section{Bibliografía}

AGAMBEN, G. (2007). Infancia e historia. Buenos Aires: Adriana Hidalgo.

ARENDT, H. (2001). ¿Qué es la política? Buenos Aires: Paidós.

BECHARA, A. (2013). Familia y Discapacidad. Padres y profesionales/docentes: un encuentro posible. Buenos Aires: Noveduc.

BENJAMIN, W. (2013). Libro de los Pasajes. Madrid: Akal.

BENJAMIN, W. (2005). Tesis sobre la Historia y otros Fragmentos. México: Contrahistorias.

BUTLER, J. (2012) Marcos de guerra. Las vidas lloradas. Buenos Aires: Paidos.

CANGUILHEM, G. (2009). Lo Normal y lo Patológico. México: Siglo XXI.

CAPURRO, R. (2004). Del sexo y su sombra, del "Misterioso Hermafrodita" de Michel Foucault. México: Epeele, École lacanienne de psycanalyse.

DERRIDA, J., y Roudinesco, E. (2001) Y mañana qué... Buenos Aires: Fondo de Cultura Económica.

DERRIDA, J. (1998). Políticas de la Amistad seguido de El oído de Heidegger. Madrid: Trotta.

FREUD, S. (2001). Tres ensayos de teoría sexual. v. 7 (1901-1905). Buenos Aires, Amorrortu.

FREUD, S. (2001). El malestar en la cultura, v. 21 (1927-1931). Buenos Aires, Amorrortu.

FOUCAUlT, M. (1967). Historia de la locura en la época clásica. México: Fondo de Cultura Económica.

FOUCAULT, M. (2007). El poder psiquiátrico. Buenos Aires: Fondo de Cultura Económica.

HEIDEGGER, M. (1964). Qué Significa Pensar. Buenos Aires: Nova.

HEIDEGGER, M. (2008). La época de la imagen del mundo. España: Alianza.

HORKHEIMER, M. (1973). Crítica de la razón instrumental. Buenos Aires: Editorial Sur. JACOBO, Z. (2015). La ceguera como mirada in-visible. Desafío de la discapacidad. Revista Entre ideas, v. 4, n. 1, p. 125-142.

JACOBO, Z. (2013). Discapacidad y Discriminación". En Estado de conocimiento. . Capítulo 7, Área 17: Convivencia, Disciplina y Violencia en las Escuelas. p. 279-322. México: ANUIES-COMIE. 
JACOBO, Z. (2015). Hacia el pensar de la diferencia. Una propuesta de subversión a la discapacidad, Revista Inclusiones (electrónica) ISSN 0719-4706, Vol. 2, Núm. 2/ AbrilJunio págs. 166 a la 175, Universidad de los Lagos, Campus Santiago, Chile JACOBO, Z. (2015). Inclusión, Diversidad y Subjetividad, 1er. Encuentro Inclusión y Diversidad en la Escuela: Memorias del Primer Encuentro Internacional, ISSSN 24632473 (en línea), Recopilación: Mabel Farfán Martínez. Ibagué: Universidad del Tolima.

JACOBO, B. E. Z. (1987). El juego de la racionalidad en los discursos educativos y curriculares. Tesis de Maestría, México: DIE-CINVESTAV

JACOBO, Z. (2012). Las paradojas de la integración/inclusión en las prácticas educativas. Efectos de discriminación o lazo social. Buenos Aires: Noveduc.

JACOBO, Z. (2008) Discapacidad y subjetividad". Revista latinoamericana de Estudios Educativos. v. 38,. 233-244, México.

JACOBO, Z. (2010). ¿De qué ética hablamos, de la Inclusión o de la Diferencia. Sujeto, Educción Especial e Integración, v. 8. México: FESI-UNAM.

LACAN J. (1987). Los cuatro conceptos fundamental del psicoanálisis. Seminario 11. México: Paidós.

LACAN, J. (2008). De un Otro al otro. Seminario 16. Buenos Aires: Paidós.

LACAN, J. (2014). El deseo y su interpretación. Seminario 6. (1958-1959). Buenos Aires: Paidós.

LACAN, J. (1999). Las formaciones del inconsciente. Seminario 5. (1957-1958). Buenos Aires: Paidós.

LACAN, J. (2009). El mito individual del Neurótico. Poesía y Verdad en la neurosis. México: Paidós, p. 11-52.

LACAN, J. (2014). Seminario El deseo y su interpretación. México: Paidós.

LEVINAS, E. (1991). Ética e Infinito. Madrid: La balsa de la medusa

LEVINAS, E. (2000). La Huella del Otro. Madrid: Alfaguara, Taurus.

MÈLICH, J. C. (2010). Ética de la compasión. Barcelona: Herder.

Recibido en: 10.08.2016

Aprobado en: 17.08 .2016 